\title{
Research on Retailer's Dual Channel Multi-Product Bundle Sales Pricing
}

\author{
Rui Li, Huaili Chen \\ Logistics Science and Engineering Research Institute, Shanghai Maritime University, Shanghai, China \\ Email: lizi122705@163.com
}

How to cite this paper: $\mathrm{Li}, \mathrm{R}$. and Chen, H.L. (2019) Research on Retailer's Dual Channel Multi-Product Bundle Sales Pricing. American Journal of Industrial and Business Management, 9, 1506-1523. https://doi.org/10.4236/ajibm.2019.96100

Received: May 27, 2019

Accepted: June 27, 2019

Published: June 30, 2019

Copyright $\odot 2019$ by author(s) and Scientific Research Publishing Inc. This work is licensed under the Creative Commons Attribution International License (CC BY 4.0).

http://creativecommons.org/licenses/by/4.0/

(c) (i) Open Access

\begin{abstract}
From the perspective of consumers, a monopolistic retailer is considered to sell two differentiated products in different sales modes: physical channel and online channel. In the case of separate sales, considering consumers' channel and product preference, the same price of the same product is set in different channels to reduce channel conflicts caused by price differences among consumers. In the case of bundling, product bundling should be considered in network channels, and two products should be sold separately in physical channels. The analysis shows that the bundling strategy is better than the separate selling strategy. It can be seen from the numerical analysis that with the increase of the substitution degree of the bundled products, the demand and profit of the bundled sales strategy will gradually increase with the increase of the substitution degree. In addition, it is also found that the marginal cost of sales in the channel has a great impact on the two sales modes. Since the marginal cost of sales in the physical channel is greater than the marginal cost of sales in the network channel, it is only in the network channel that bundling is adopted, and the separate sales in the physical channel will enable the retailer to obtain more profits.
\end{abstract}

\section{Keywords}

Retailer's Double Channel, Bundle Sales, Marginal Cost of Sales

\section{Introduction}

The rapid development of the Internet has caused great changes in the form of sales of enterprises. Manufacturers have opened up direct sales channels and the emergence of online retailers, which are all products of the Internet. Due to the change in sales form, it is a huge impact on the traditional retail industry. Manufacturers open up direct sales channels and compete with traditional retailers. 
At the same time, online retailers have lower input costs for selling products in online channels than physical channels. The form attracts customers and further divides the market share of traditional retailers. In a situation of fierce competition, traditional retailers have to open up network channels to avoid more profit damage. The domestic enterprises that initially opened up network channels were Suning and Gome. After opening up the network channel, Suning lacked the sales experience of the network channel, so it made a long and difficult exploration of the channel pricing. For the same product, the online and offline differentiated pricing strategy was adopted at the beginning, and the same price strategy was gradually adopted for the same product.

The first chapter is mainly the background introduction of the article, the second chapter is the research status of the article, and the main content of the article is drawn through the research status. The retailer adopts the bundled sales situation through dual channels. The third chapter is the establishment of the model, considering the consumption. Channel preferences and product preferences, based on utility maximization to establish a profit function, and then get the best retail price; the fourth chapter mainly considers the marginal cost of sales and the degree of substitution on demand and profit; the fifth chapter is the summary of this article and outlook.

\section{Related Literature}

Guo Chunrong et al. (2009) [1], Guo (2012) [2], Xu Ning (2013) [3], Zheng Wenjun et al. (2014) [4] show that when the channel adopts the same price strategy will reduce the channel The alternative between the two, effectively achieve coordination between the channels. And found that from the perspective of consumers, the impact of retailers adopting the same price strategy on channel conflicts is studied. The double-line price can guide consumers from paying attention to commodity prices to paying attention to the comprehensive value of the entire consumption process. The experience also eases conflicts between retailer channels. Although adopting the same price strategy among channels to reduce the price comparison between channels, consumers can have more product experience, effectively avoid channel conflicts, and achieve channel coordination. However, after adopting the same price strategy, retailers' profits have not improved. Instead, it has fallen. The reason for this phenomenon is that the sales cost of the physical channel is higher than the sales cost of the network channel, which in turn affects the retailer's profit. Tsay \& Agrawal (2004) [5], Yuan Chun et al. (2014) [6], Chen Guopeng et al. (2016) [7], Liu Hailong (2016) [8] studied the conflict and coordination of channels, and found that although the same price strategy would Let the channels coordinate effectively, but they can't optimize the profit of the company. It is effective to adopt the same price strategy only when the difference between the channels is small. In real life, retailers often sell not only a product but a variety of products. In this case, it is necessary to coordinate the difference between the product and the product. For 
the sale of a variety of products, scholars study the sales strategy of bundled products. Adams \& Yellen (1976) [9] studied the case of a monopoly retailer selling multiple products, considering three sales methods, separate sales, pure bundle sales, and hybrid bundle sales, and found that profits would increase after the implementation of the bundled strategy. Bundling for more than two products is a complex issue. Gaeth et al. (1991) [10] studied the impact of bundled products on consumer utility from the perspective of consumers, and the bundled products would allow consumers to change the price of bundled products. It also proposes to increase the consumer's effectiveness on the product when the product and service are bundled. Eppen \& Hanson (1991) [11] analyzed the advantages of bundled products for separate sales models and found that bundled sales can effectively save costs. Pan Lin et al. (2016) [12] studied the pricing model of multi-products. Consider both the manufacturer and the retailer. Four scenarios were discussed separately, manufacturers bundled and sold separately, retailers bundled and sold separately. Research shows that manufacturers are selling separately, which is optimal for manufacturers, and the retailer's sales model will be affected by the complementarity and marginal profit between the two products, the reduction of complementarity and the reduction of marginal revenue, retail The Chamber of Commerce is gradually biased towards bundling pricing. Yan Fanga \& Lijun Sun, \& Ying Gao (2017) [13] found that consumers with low consumption levels prefer bundled products consisting of more low-priced items, and products with higher cost levels should be bundled in smaller bundle sizes and High price. Wang Huifang (2018) [14] studied the situation in which a manufacturer provides a single product to a retailer in a dual-channel environment, and the retailer sells two products, considering the retailer's separate sales and bundled sales. Studies have shown that when a manufacturer sells a product at a higher price, the retailer's bundling is better than a separate sale. Although there are many researches on multi-product pricing scholars, most product differentiation pricing is concentrated on single-channel product sales, as well as between manufacturers and retailers. It does not take into account the fact that multiple products are sold in retailers' dual channels.

This article considers the situation in which retailers sell two products. From the perspective of consumers, we discuss two situations separately. First, we sell two independent products in physical channels and online channels. Consumers have certain preferences for products and channels, according to consumption. The user's own utility chooses which product to buy in the channel; secondly, considers the bundling of the two products in the network channel, and separately sells the two products in the physical channel. Similarly, the consumer maximizes the products and channels according to the utility.

\section{The Model}

\subsection{Parameter Design and Model Assumptions}

1) Parameter Design (Table 1) 
Table 1. Parameter and variable.

\begin{tabular}{cc}
\hline Parameter & Meaning \\
\hline$p_{1}$ & The price of selling product 1 when selling separately \\
$p_{2}$ & The price of selling product 2 when selling separately \\
$p_{1}^{b}$ & The price of selling product 1 when bundled sales \\
$p_{2}^{b}$ & The price of selling product 1 when bundled sales \\
$p_{12}$ & The price of the product bundled online \\
$\omega$ & The consumer's sensitivity to the degree of substitution of the bundled product \\
$\theta$ & Consumers' preference for physical channels \\
$a$ & There of substitution \\
$v$ & The value of product 1 \\
$\alpha v$ & Marginal cost of sales in physical channels \\
$c_{t}$ & Marginal cost of sales in online channels \\
$c_{e}$ &
\end{tabular}

\section{2) Model Assumptions}

Suppose there is a monopoly retailer in the market, adding online channels to sell products in the original physical channels, and selling two products, product 1 and product 2 in the network channel and retail channels. At the same time, the value of products 1 and 2 is different. The value of product 1 is $v$, and the value of product 2 is $\alpha$ times the value of product 1 , then the value of product 2 is $\alpha v, v$ follows the uniform distribution of $[0,1]$. First, consider the case where the two products are sold separately, that is, the two products are separately sold in the physical channel and the network channel, and then the product is bundled in the network channel, and the physical channel is separately sold, as shown below (Figure 1 and Figure 2).

\subsection{Model Establishment and Solution When Selling Separately}

The retailer sells the two products through the channel and adopts the product price strategy, that is, the price of the product 1 is the same in the physical channel and the network channel, and the sales price of the same product 2 in the respective channels is also the same. The price of selling product 1 and product 2 is $p_{1}, p_{2}$. Consumers' preference for physical channels is $\rho$. Consumers' preference for network channels is $1-\rho$. The utility of the consumer to purchase product 1 is $u_{1}=v-p_{1}$. The utility of the consumer to purchase product 2 is $u_{2}=\alpha v-p_{2}$. At the same time, the consumer's preference for product 1 when making a purchase is $a(0<a<1)$, The preference ratio for product 2 is $(1-a)$. Choose to buy when the consumer utility is greater than zero. The specific decision process is as follows.

1) Consumers prefer product 1 and physical channels, then when $v-p_{1}>0$, 


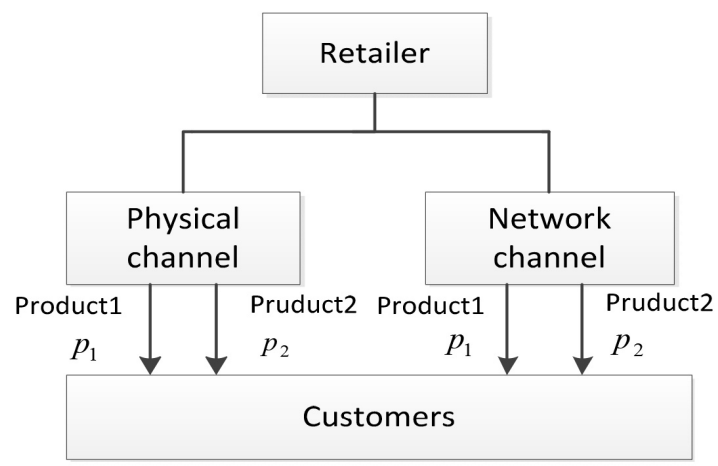

Figure 1. Separate sales.

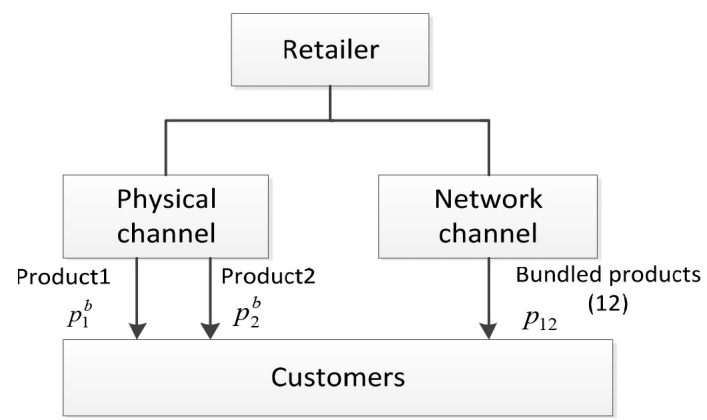

Figure 2. Bundle sales.

purchase product 1; otherwise exit the market, because this part of the consumer is biased towards the physical channel, the demand for product 1 is $\rho a\left(1-p_{1}\right)$.

2) Consumers prefer product 1 and network channels, then when $v-p_{1}>0$, buy product 1; otherwise, exit the market, because this part of the consumer is biased towards the network channel, the demand for product 1 is $(1-\rho) a\left(1-p_{1}\right)$;

3) Consumers prefer product 2 and physical channels. Then when $\alpha v-p_{2}>0$, buy product 2; otherwise exit the market. This part of the consumer is biased towards the physical channel, so the demand for product 2 is $\rho(1-a)\left(1-\frac{p_{2}}{\alpha}\right)$;

4) Consumers prefer product 2 and network channels, then when $\alpha v-p_{2}>0$, buy product 2; otherwise exit the market. This part of the consumer is biased towards the network channel, so the demand for product 2 is $(1-\rho)(1-a)\left(1-\frac{p_{2}}{\alpha}\right)$. The demand for products 1 and 2 can be obtained from the consumer's decision as follows:

$$
\begin{aligned}
D_{1} & =D_{1 t}+D_{1 e}=\rho a\left(1-p_{1}\right)+(1-\rho) a\left(1-p_{1}\right)=a\left(1-p_{1}\right) \\
D_{2} & =D_{2 t}+D_{2 e}=\rho(1-a)\left(1-\frac{p_{2}}{\alpha}\right)+(1-\rho)(1-a)\left(1-\frac{p_{2}}{\alpha}\right) \\
& =(1-a)\left(1-\frac{p_{2}}{\alpha}\right)
\end{aligned}
$$

According to the demand function, the retailer's profit function when selling 
separately is as follows:

$$
\begin{aligned}
\Pi= & \rho a\left(1-p_{1}\right)\left(p_{1}-c_{t}\right)+(1-\rho) a\left(1-p_{1}\right)\left(p_{1}-c_{e}\right) \\
& +\rho(1-a)\left(1-\frac{p_{2}}{\alpha}\right)\left(p_{2}-c_{t}\right)+(1-\rho)(1-a)\left(1-\frac{p_{2}}{\alpha}\right)\left(p_{2}-c_{e}\right)
\end{aligned}
$$

Proposition 1: There are optimal prices $p_{2}^{*}$ and $p_{2}^{*}$, which make the retailer's profit optimal. And the best price is:

$$
\begin{aligned}
& p_{1}^{*}=\frac{1+c_{e}+\rho c_{t}-\rho c_{e}}{2} \\
& p_{2}^{*}=\frac{\alpha+c_{e}+\rho c_{t}-\rho c_{e}}{2}
\end{aligned}
$$

\section{Proof 1 in Appendix 1:}

According to the optimal price, the optimal profit at this time is:

$$
\Pi^{*}=\frac{(1-a)\left(c_{e}-\alpha-\rho c_{e}+\rho c_{t}\right)^{2}}{4 \alpha}+\frac{a\left(c_{e}-\rho c_{e}+\rho c_{t}-1\right)^{2}}{4}
$$

\subsection{Model Establishment and Solution in Bundled Sales}

When retailers are doing bundled sales, they mainly use online bundling and offline sales. The price of the product bundled online is $p_{12}$. Consumers value a bundled product as $\beta v$, where $\alpha<\beta<1$. The bundled product is a substitute for Product 1 and Product 2, with a degree of substitution $\theta(0<\theta<1)$. The higher the degree of substitution of the bundled product, the greater the consumer's effectiveness on the bundled product, and the consumer's sensitivity to the degree of substitution of the bundled product is $\omega$. The utility of bundled products purchased by consumers online is $u_{12}=\beta v-p_{12}+\omega \theta$.

In order to distinguish between two different situations, it is assumed that the price of product 1 is $p_{1}^{b}$ and the price of product 2 is $p_{2}^{b}$ under bundling, so the utility of purchasing product 1 is $u_{1}^{b}=v-p_{1}^{b}$, and the utility of purchasing product 2 is $u_{2}^{b}=\alpha v-p_{2}^{b}$. The consumer's decision-making process is as follows.

In the previous analysis, because the online and offline adopting the channel price strategy, the utility of the consumers in different channels is the same. Only the consumer's channel preference and product preference should be considered, and the product with positive utility should be selected. However, in the bundle sale, there are three products, product 1, product 2 and bundled product (12). Consumers who prefer Product 1 have two choices in this case: first, select product 1, and second, select bundled product (12). Similarly, consumers who prefer product 2 also have two choices: first, select product 2; second, select bundled product (12). Consumer choice is based on maximizing their utility.

First consider the consumer choice of preference product 1 . The utility of the consumer to purchase product 1 is $u_{1}^{b}=v-p_{1}^{b}$, The utility of purchasing bundled products (12) is $u_{12}=\beta v-p_{12}+\omega \theta$.

The demand function is obtained by comparison of the utility as follows: 


$$
\begin{aligned}
D_{1}^{b}=a \cdot \begin{cases}1-\frac{p_{1}^{b}-p_{12}+\omega \theta}{1-\beta} & p_{1}^{b} \geq \frac{p_{12}-\omega \theta}{\beta} \\
1-p_{1}^{b} & p_{1}^{b}<\frac{p_{12}-\omega \theta}{\beta}\end{cases} \\
D_{12}^{1}=a \cdot \begin{cases}\frac{p_{1}^{b}-p_{12}+\omega \theta}{1-\beta}-\frac{p_{12}-\omega \theta}{\beta} & p_{1}^{b} \geq \frac{p_{12}-\omega \theta}{\beta} \\
0 & p_{1}^{b}<\frac{p_{12}-\omega \theta}{\beta}\end{cases}
\end{aligned}
$$

Next, consider the consumer choice of preference product 2 , the utility of the consumer purchase product 2 is $u_{2}^{b}=\alpha v-p_{2}^{b}$, The utility of purchasing bundled products (12) is $u_{12}=\beta v-p_{12}+\omega \theta$.

The demand function is obtained by comparison of the utility as follows:

$$
\begin{aligned}
& D_{2}^{b}=(1-a) \cdot \begin{cases}\frac{p_{12}-p_{2}^{b}-\omega \theta}{\beta-\alpha}-\frac{p_{2}^{b}}{\alpha} & p_{2}^{b} \leq \frac{\alpha\left(p_{12}-\omega \theta\right)}{\beta} \\
0 & p_{2}^{b}>\frac{\alpha\left(p_{12}-\omega \theta\right)}{\beta}\end{cases} \\
& D_{12}^{2}=(1-a) \cdot \begin{cases}1-\frac{p_{12}-p_{2}^{b}-\omega \theta}{\beta-\alpha} & p_{2}^{b} \leq \frac{\alpha\left(p_{12}-\omega \theta\right)}{\beta} \\
1-\frac{p_{12}-\omega \theta}{\beta} & p_{2}^{b}>\frac{\alpha\left(p_{12}-\omega \theta\right)}{\beta}\end{cases}
\end{aligned}
$$

In order for each product to have sales, the demand function for each product is as follows:

$$
\begin{gathered}
D_{1}^{b}=a\left(1-\frac{p_{1}^{b}-p_{12}+\omega \theta}{1-\beta}\right) \\
D_{2}^{b}=(1-a)\left(\frac{p_{12}-p_{2}^{b}-\omega \theta}{\beta-\alpha}-\frac{p_{2}^{b}}{\alpha}\right) \\
D_{12}=D_{12}^{1}+D_{12}^{2} \\
=a\left(\frac{p_{1}^{b}-p_{12}+\omega \theta}{1-\beta}-\frac{p_{12}-\omega \theta}{\beta}\right)+(1-a)\left(1-\frac{p_{12}-p_{2}^{b}-\omega \theta}{\beta-\alpha}\right)
\end{gathered}
$$

Retailer profits are as follows:

$$
\begin{aligned}
\Pi^{b}= & a\left(1-\frac{p_{1}^{b}-p_{12}+\omega \theta}{1-\beta}\right)\left(p_{1}^{b}-c_{t}\right)+(1-a)\left(\frac{p_{12}-p_{2}^{b}-\omega \theta}{\beta-\alpha}-\frac{p_{2}^{b}}{\alpha}\right)\left(p_{2}^{b}-c_{t}\right) \\
+\left[a\left(\frac{p_{1}^{b}-p_{12}+\omega \theta}{1-\beta}-\frac{p_{12}-\omega \theta}{\beta}\right)+(1-a)\left(1-\frac{p_{12}-p_{2}^{b}-\omega \theta}{\beta-\alpha}\right)\right]\left(p_{12}-c_{e}\right) & \\
\text { s.t } p_{1}^{b} & \geq \frac{p_{12}-\omega \theta}{\beta} \\
p_{2}^{b} & \leq \frac{\alpha\left(p_{12}-\omega \theta\right)}{\beta}
\end{aligned}
$$

Proposition 2: Retailer profit $\Pi^{b}$ is a joint concave function for $p_{1}^{b}, p_{2}^{b}$ 
and $p_{12}$.

Proof 2 in Appendix 2:

Proposition 3: There are optimal prices $a, b$ and $c$ such that the profit function has a maximum value and the optimal price is: $p_{1}^{b}, p_{2}^{b}$ and $p_{12}$.

Proof 3 in Appendix 3:

At this point, the retailer's profit is:

$$
\begin{aligned}
\Pi^{b}= & \left(\beta-c_{e}+\omega \theta\right)\left[\frac{(1-a)\left(\beta-c_{e}+c_{t}-\alpha+\omega \theta\right)}{4(\beta-\alpha)}+\frac{a\left(\beta c_{t}-c_{e}+\omega \theta\right)}{4 \beta(1-\beta)}\right] \\
& +\frac{(1-a)\left(c_{t}-\alpha\right)\left(\beta c_{t}-\alpha c_{e}+\alpha \omega \theta\right)}{4 \alpha(\beta-\alpha)} \\
& -\frac{a\left(1-c_{t}\right)\left(\beta-c_{e}+c_{t}+\omega \theta-1\right)}{4(1-\beta)}
\end{aligned}
$$

\subsection{Comparative Analysis}

The sales volume of product 1 obtained according to formula (4) when selling separately is:

$$
a\left(1-p_{1}^{*}\right)=a\left(1-\frac{1+c_{e}+\rho c_{t}-\rho c_{e}}{2}\right)=a\left(\frac{1}{2}-\frac{c_{e}+\rho c_{t}-\rho c_{e}}{2}\right)
$$

Product 2 sales are:

$$
(1-a)\left(1-\frac{p_{2}}{\alpha}\right)=(1-a)\left(\frac{1}{2}-\frac{c_{e}+\rho c_{t}-\rho c_{e}}{2 \alpha}\right)
$$

The total sales of Product 1 when bundled are:

$$
D_{1}^{b}+D_{12}=\frac{a\left(\beta-c_{e}+\omega \theta\right)}{2 \beta}+\frac{(1-a)\left(\beta-c_{e}+c_{t}-\alpha+\omega \theta\right)}{2(\beta-\alpha)}
$$

The total sales of Product 2 when bundled are:

$$
D_{2}^{b}+D_{12}=\frac{(1-a)\left(\alpha-c_{t}\right)}{2 \alpha}+\frac{a\left(\beta c_{t}-c_{e}+\omega \theta\right)}{2 \beta(1-\beta)}
$$

The difference in total sales between the two cases:

$$
\begin{aligned}
\Delta D_{1}= & D_{1}^{b}+D_{2}^{b}+2 D_{12}-\left(D_{1}+D_{2}\right) \\
= & \frac{a\left(\beta-c_{e}+\omega \theta\right)}{2 \beta}+\frac{(1-a)\left(\beta-c_{e}+c_{t}-\alpha+\omega \theta\right)}{2(\beta-\alpha)} \\
& -a\left(\frac{1}{2}-\frac{c_{e}+\rho c_{t}-\rho c_{e}}{2}\right)+\frac{(1-a)\left(\alpha-c_{t}\right)}{2 \alpha} \\
& +\frac{a\left(\beta c_{t}-c_{e}+\omega \theta\right)}{2 \beta(1-\beta)}-(1-a)\left(\frac{1}{2}-\frac{c_{e}+\rho c_{t}-\rho c_{e}}{2 \alpha}\right) \\
= & \frac{a\left(\omega \theta-c_{e}+\beta c_{e}+\beta \rho c_{t}-\beta \rho c_{e}\right)}{2 \beta}+\frac{(1-a)\left(\beta-c_{e}+c_{t}-\alpha+\omega \theta\right)}{2(\beta-\alpha)} \\
& +\frac{(1-a)\left[\alpha\left(c_{e}+\rho c_{t}-\rho c_{e}\right)-c_{t}\right]}{2 \alpha}+\frac{a\left(\beta c_{t}-c_{e}+\omega \theta\right)}{2 \beta(1-\beta)}
\end{aligned}
$$

\section{Proposition 4:}




$$
\begin{gathered}
0<\frac{\left[(1-a)\left(\alpha^{2} \rho-\alpha-\alpha^{2}-\beta\right)+a \beta(2-2 \beta-\beta \rho)\right] c_{e}}{\omega \beta^{2} a-\omega(1-a)(\beta-\alpha)} \\
+\frac{\left[(1-a)\left(2 \alpha-\alpha^{2} \rho+\beta\right)-a \beta \rho\right] c_{t}-(\alpha+\beta)^{2}}{\omega \beta^{2} a-\omega(1-a)(\beta-\alpha)}<1
\end{gathered}
$$

At $\theta \in\left(0, \theta^{*}\right)$, when sold separately, the sales of the product are greater than the sales of the product at the time of bundled sales. At $\theta \in\left(\theta^{*}, 1\right)$, when sold separately, the sales of the product are less than the sales of the product at the time of the bundle.

\section{Proof 4 in Appendix 4:}

From Proposition 4, when the degree of substitution between the bundled product and the product 1, 2 is small, the consumer's demand for the bundled product is not large, and since the binding strategy is adopted on the line, the degree of substitution is small, so the consumer purchases online. The number of products is reduced. At this time, the adoption of the bundling strategy does not increase the sales of the products, but also reduces the sales of the products. On the other hand, when the degree of substitution between the two products is higher, the utility of the consumer to purchase the bundled product increases, and the price at which the consumer purchases the bundled product is lower than the price at which the two products are purchased at the same time, therefore, the demand of the consumer Will increase. The difference in profit between the two cases is:

$$
\begin{aligned}
\Delta \Pi= & \Pi_{b}-\Pi \\
= & \left(\beta-c_{e}+\omega \theta\right)\left[\frac{(1-a)\left(\beta-c_{e}+c_{t}-\alpha+\omega \theta\right)}{4(\beta-\alpha)}+\frac{a\left(\beta c_{t}-c_{e}+\omega \theta\right)}{4 \beta(1-\beta)}\right] \\
& +\frac{(1-a)\left(c_{t}-\alpha\right)\left(\beta c_{t}-\alpha c_{e}+\alpha \omega \theta\right)}{4 \alpha(\beta-\alpha)} \\
& -\frac{a\left(1-c_{t}\right)\left(\beta-c_{e}+c_{t}+\omega \theta-1\right)}{4(1-\beta)}-\frac{(1-a)\left(c_{e}-\alpha-\rho c_{e}+\rho c_{t}\right)^{2}}{4 \alpha} \\
& -\frac{a\left(c_{e}-\rho c_{e}+\rho c_{t}-1\right)^{2}}{4}
\end{aligned}
$$

Simplify equation to get:

$$
\begin{aligned}
\Delta \Pi= & {\left[\frac{1-a}{4(\beta-\alpha)}+\frac{a}{4 \beta(1-\beta)}\right] \omega^{2} \theta^{2}+\left[\frac{(1-a)\left(\beta-c_{e}+c_{t}-\alpha\right)}{2(\beta-\alpha)}\right.} \\
& \left.-\frac{a\left(c_{e}-\beta c_{t}\right)}{2 \beta(1-\beta)}\right] \omega \theta+\frac{(1-a)\left(\beta c_{t}^{2}+\alpha c_{e}^{2}\right)}{4(\beta-\alpha) \alpha}+\frac{a c_{e}^{2}}{4 \beta(1-\beta)} \\
& +\frac{a+\beta(1-a)}{4}-\frac{(1-a) c_{e}\left(\beta-\alpha+c_{t}\right)}{2(\beta-\alpha)}-\frac{a c_{t}\left(2-c_{t}\right)}{4(1-\beta)} \\
& -\frac{(1-a)\left(c_{e}-\alpha-\rho c_{e}+\rho c_{t}\right)^{2}}{4 \alpha}-\frac{a\left(c_{e}-\rho c_{e}+\rho c_{t}-1\right)^{2}}{4}
\end{aligned}
$$

The first derivative of the Equation (21) is obtained: 


$$
\begin{aligned}
A(\theta)=\frac{\partial \Pi}{\partial \theta}= & \omega\left\{\left[\frac{1-a}{2(\beta-\alpha)}+\frac{a}{2 \beta(1-\beta)}\right] \omega \theta\right. \\
& \left.+\left[\frac{(1-a)\left(\beta-c_{e}+c_{t}-\alpha\right)}{2(\beta-\alpha)}-\frac{a\left(c_{e}-\beta c_{t}\right)}{2 \beta(1-\beta)}\right]\right\}
\end{aligned}
$$

Because of $0<\theta<1,\left[\frac{1-a}{2(\beta-\alpha)}+\frac{a}{2 \beta(1-\beta)}\right] \omega>0$, so:

$$
\begin{aligned}
A(1) & >A(0)=\left[\frac{(1-a)\left(\beta-c_{e}+c_{t}-\alpha\right)}{2(\beta-\alpha)}-\frac{a\left(c_{e}-\beta c_{t}\right)}{2 \beta(1-\beta)}\right] \omega \\
& =(1-\beta) \beta(\beta-\alpha)+\beta c_{t}(1-\beta-\beta+\alpha)+\left(\beta^{2}-\alpha\right) c_{e}>0
\end{aligned}
$$

$\theta \in(0,1)$ Monotonically increasing in $\Delta \Pi$,

$$
\begin{aligned}
\Delta \Pi(0) & =\frac{(1-a)\left(\beta c_{t}^{2}+\alpha c_{e}^{2}\right)}{4(\beta-\alpha) \alpha}+\frac{a c_{e}^{2}}{4 \beta(1-\beta)}+\frac{a+\beta(1-a)}{4} \\
& -\frac{(1-a) c_{e}\left(\beta-\alpha+c_{t}\right)}{2(\beta-\alpha)}-\frac{a c_{t}\left(2-c_{t}\right)}{4(1-\beta)} \\
& -\frac{(1-a)\left(c_{e}-\alpha-\rho c_{e}+\rho c_{t}\right)^{2}}{4 \alpha}-\frac{a\left(c_{e}-\rho c_{e}+\rho c_{t}-1\right)^{2}}{4} \\
& >0
\end{aligned}
$$

Then $\Delta \Pi>0$ is always established on $\theta \in(0,1)$. That is, the profit at the time of bundled sales is greater than the profit at the time of separate sales.

\section{Numerical Example}

Suppose $\beta=0.8, \alpha=0.6, c_{t}=0.025, \quad c_{e}=0.0125, \rho=0.6, \quad \theta=0.7$, $a=0.5, \omega=0.4$.

1) The impact of marginal cost of sales on profits, as shown below:

It can be seen from Figure 3 that marginal cost has a greater impact on profit, especially when adopting a bundled sales strategy, when the marginal sales cost of the network channel is higher than the marginal cost of sales of the physical channel, the bundled sales cannot bring the profit to the retailer. Conversely, profits may be damaged. In real life, retailers have more manpower and material resources in the physical channel, and network channels do not require much manpower and material resources. Therefore, online channels tend to be lower than physical channels in terms of input costs, thus $c_{e}<c_{t}$. It can also be seen from the figure that bundling sales at this time can bring more profits to the enterprise. That is to take the bundled strategy in the network channel; the way the entity channel is sold separately can bring more benefits to the enterprise.

2) The impact of the degree of substitution on demand and profit

Through data analysis, it can be seen from Figures 4-6 that the adoption of the bundling strategy can increase the sales volume of the product 1 with higher value, and for the product with a slightly lower value, when the degree of 


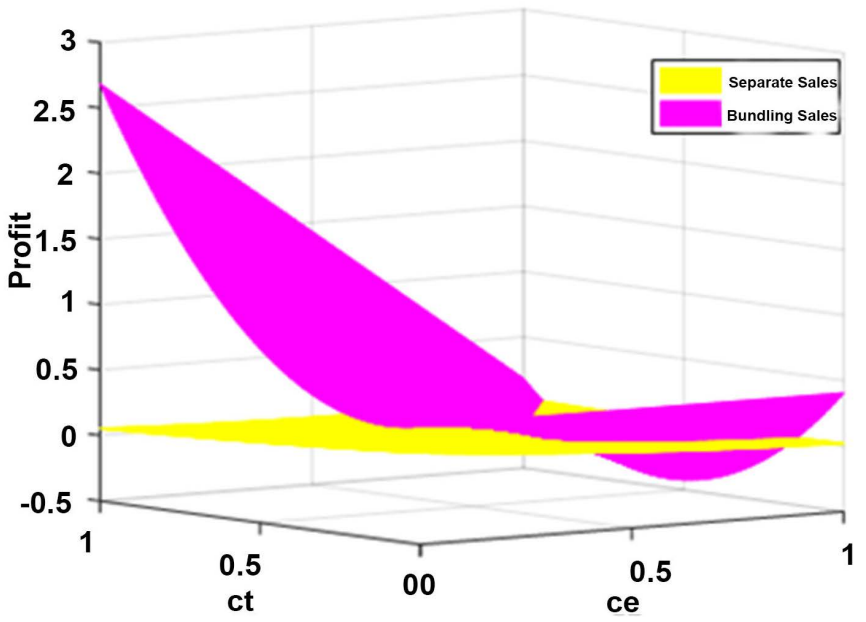

Figure 3. The impact of marginal cost on profit.

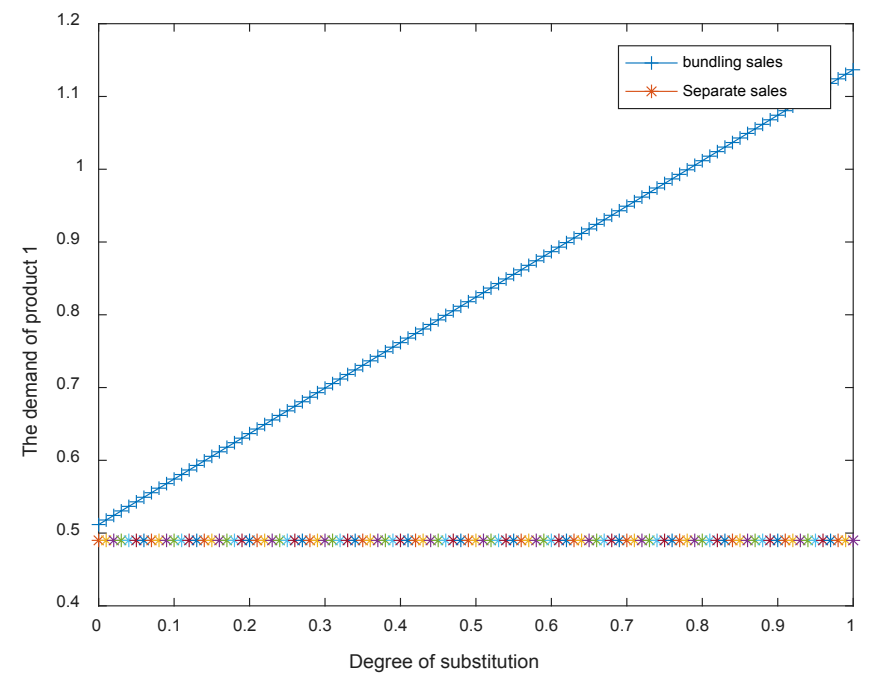

Figure 4. The effect of degree of substitution on product 1 .

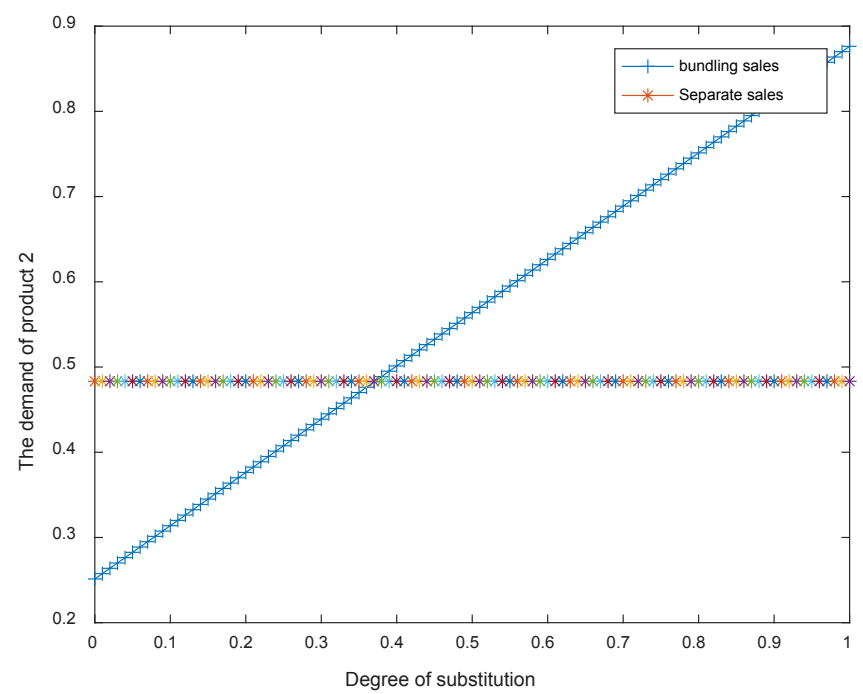

Figure 5. The effect of degree of substitution on product 2. 


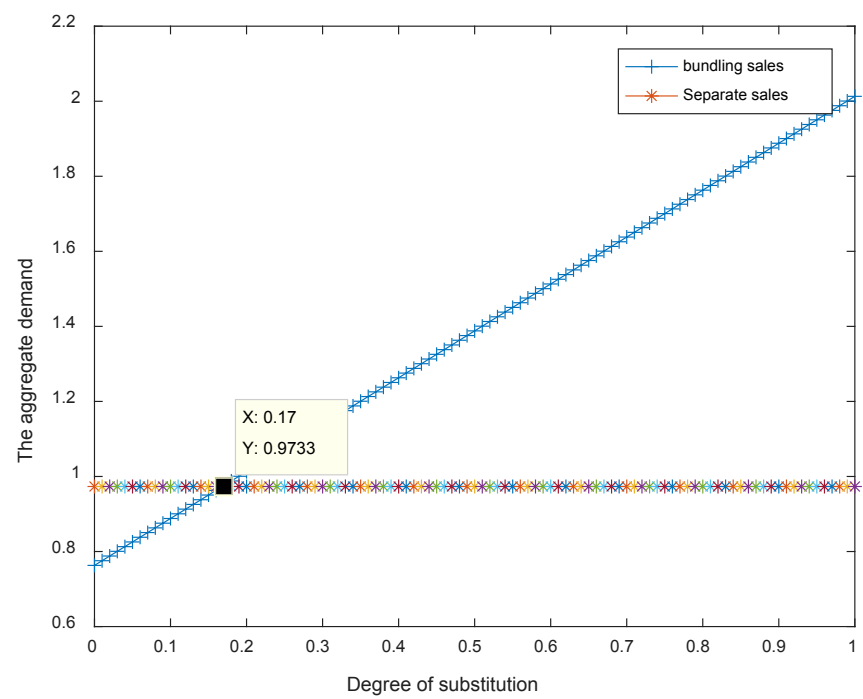

Figure 6. The effect of degree of substitution on aggregate demand.

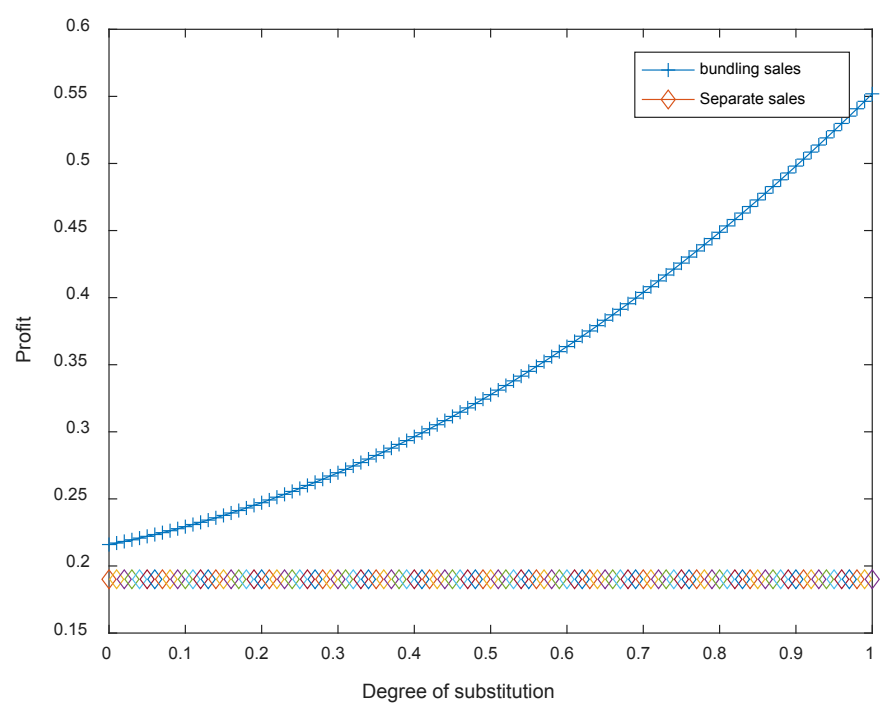

Figure 7. The effect of degree of substitution on profit.

substitution is relatively small, the bundling strategy is adopted to reduce the product 2 On the one hand, because the price of the bundled product will be higher than the price of the product 2, the degree of substitution is small, and the consumer who prefers the product 2 has little effect on the bundled product, and therefore does not choose to purchase the bundled product. When the degree of substitution is high, whether it is the consumer who prefers product 1 or the consumer who prefers product 2 , the utility of the bundled product will increase, and the consumer will transfer to purchase the bundled product and increase the sales of the two products. At the same time, it can be seen from Figure 4 that when $\Delta D=0$, there is $\theta^{*}=0.17$.

As can be seen from Figure 7, as the degree of substitution of Product 1 and Product 2 increases, the profit of bundled sales will gradually increase, and the 
adoption of bundled sales will enable retailers to obtain more profits. Combing with the impact of the degree of substitution on demand, the total demand for the product increases when the degree of substitution is higher, and the price of the bundled product increases, thus increasing the profit of the retailer.

\section{Conclusions}

From the perspective of consumers, this paper establishes a consumer utility function and considers two sales models. When the products are sold separately in the physical channel and the network channel, the consumer's channel preferences and product preferences are considered, and the consumer utility is established. From the consumer's point of view, the consumer utility function is obtained, and the demand function is established according to the utility maximization, and then the profit function is established, and the goal is to maximize the profit of the retailer. It is the result of a game between consumers and retailers. When product bundles are implemented in the network channel and the physical channels are sold separately, the consumer's product preferences are considered on the one hand, and the bundled products and products 1, 2 are further demanded by comparing the bundled products and the effects of the products 1, 2. Functions get the optimal pricing for bundled products and products 1, 2. Through comparative analysis, the following conclusions are obtained:

1) The marginal cost of sales of physical channels and network channels has a greater impact on profits. Due to the large cost of manpower and material resources invested in physical channels in real life, the marginal cost of sales of physical channels relative to network channels is higher. By adopting product bundles of network channels, the strategy of separate sales by physical channels can bring more profits to retailers.

2) The degree of substitution of the bundled product to the product has an obvious influence on the demand of the product. For product 1with the higher value, the implementation of the bundle will increase the sales of the product 1 , and as the degree of substitution increases, the sales volume of the product 1 is gradually increasing. For the lower value product 2 and there are fewer alternatives to bundled products, the consumer often does not choose to buy the bundled product. On the one hand, because the consumer has a preference for the product 2, on the other hand, the price of the bundled product is higher than the product. The price of 2 causes the demand for product 2 to drop. However, when the degree of substitution is high, the sales volume of product 2 is significantly improved. In the case of separate sales and bundled sales, the total demand difference is positive and negative, not only related to the degree of substitution of the bundled products to products 1,2 , but also to the value of the two products themselves. When the degree of substitution is greater than a certain value, bundled sales will greatly increase the sales of the product.

3) The degree of substitution of the bundled product to the product has a greater impact on the profit of the product. As the replacement process of the 
bundled product to the product 1, 2 increases, the benefit from the bundled strategy will gradually increase, which is greater than the benefit from the separate sale.

In short, regardless of whether the difference in value between products is obvious or not, when a retailer sells two products in two channels, the greater the degree of substitution of the bundled product is, the greater the market share and the benefit that the bundled sales strategy brings to the retailer are. When traditional retailers open up online channels to sell products, they can choose bundle pricing based on the characteristics of the products, which will make retailers more profitable.

However, the article only considers a retailer's bundling situation. The real-life situation is often more complicated such as considering the competition between multiple retailers to open up the network channel, and the supply between the retailer and the manufacturer. The pricing of the chain, as well as the more complex circumstances to consider whether the bundle can bring more benefits to the enterprise, is the direction of future research.

\section{Conflicts of Interest}

The authors declare no conflicts of interest regarding the publication of this paper.

\section{References}

[1] Guo, C. and Chen, G. (2009) Price Competition and Equilibrium Analysis of Dual Mixed Channel Distribution in Supply Chain. Chinese Management Science, 17, 65-71.

[2] Xu, N. (2013) Double-Line Same Price: Redemption of Physical Retail. Sales and Marketing (Management Edition), No. 8, 83-85.

[3] Zheng, W., Xu, L. and Li, B. (2014) Analysis of the Effect of Strong Retailers Opening up Network Channels under the Background of Online and Offline Prices. System Engineering, 32, 105-109.

[4] Guo, L. (2012) Inequity Aversion and Fair Selling. Journal of Marketing Research, 52, 77-89. https://doi.org/10.1509/jmr.12.0175

[5] Tsay, A. and Agrawal, N. (2004) Channel Conflict and Coordination in the e-Commerce Age. Production and Operation Management, 13, 93-110. https://doi.org/10.1111/j.1937-5956.2004.tb00147.x

[6] Chen, G. and Xiang, C. (2016) Research on Pricing Strategy of Dual Channel Retailers under the Environment of "Internet +". Price Theory and Practice, No. 5 , 152-155.

[7] Liu, H. (2016) Study on the Same-Price Strategy of Traditional Retailers' Online and Offline Products-Taking Suning as an Example. China's Circulation Economy, 30, 59-66.

[8] Yuan, C., Yan, L. and Chai, G. (2014) The Oligarch Dual Channel Cournot Game Model-Also on Suning's Dual Channel Same Price Strategy. Prediction, 33, 65-70.

[9] Gaeth, G.J., Levin, I.P., Chakraborry, G. and Levin, A.M. (1991) Consumer Evaluations of Multi-Product Bundles: An Information Integration Analysis. Marketing Letters, 2, 47-57. https://doi.org/10.1007/BF00435195 
[10] Adams, W.J. and Yellen, J.L. (1976) Commodity Bundling and the Burden of Monopoly. The Quarterly Journal of Economics, 90, 475-498. https://doi.org/10.2307/1886045

[11] Eppen, G.D., Hanson, W.A. and Martin, R.K. (1991) Bundling New Products, New Markets, Low Risk. Sloan Management Review, 32, 14-26.

[12] Pan, L. and Zhou, S. (2016) Multi-Product Supply Chain Pricing Strategy Considering Bundling. Operations and Management, 25, 11-17.

[13] Yan, F., Sun, L. and Gao, Y. (2017) Bundle-Pricing Decision Model for Multiple Products. Procedia Computer Science, 112, 2147-2154.

https://doi.org/10.1016/j.procs.2017.08.243

[14] Wang, H. (2018) Research on Retailer Bundling Strategy under Dual-Channel Supply Chain. Harbin Institute of Technology, Harbin. 


\section{Appendix 1}

Proof 1: For the Equation (3), the Hesse matrices for the prices $p_{1}$ and $p_{2}$ of Product 1 and Product 2 are obtained:

$$
H=\left[\begin{array}{cc}
\frac{\partial^{2} \Pi}{\partial p_{1}^{2}} & \frac{\partial^{2} \Pi}{\partial p_{1} \partial p_{2}} \\
\frac{\partial^{2} \Pi}{\partial p_{2} \partial p_{1}} & \frac{\partial^{2} \Pi}{\partial p_{2}^{2}}
\end{array}\right]=\left[\begin{array}{cc}
-2 a & 0 \\
0 & -\frac{2(1-a)}{\alpha}
\end{array}\right]
$$

First order determinant is $\left|H_{1}\right|=-2 a<0$. The second order determinant is $\left|H_{2}\right|=\frac{4 a(1-a)}{\alpha}$, because of $0<a<1$, so $\left|H_{2}\right|>0$. The Hesse-matrix is a negative definite matrix, so $\mathrm{p} 1$ and $\mathrm{p} 2$ are concave functions with respect to price.

When $\frac{\partial \Pi}{\partial p_{1}}=0, \frac{\partial \Pi}{\partial p_{2}}=0$, The profit function has an optimal value. Find the first derivative of $p_{1}$ and $p_{2}$ for Equation (3). As followed:

$$
\begin{gathered}
\frac{\partial \Pi}{\partial p_{1}}=a\left(c_{e}-2 p_{1}-\rho c_{e}+\rho c_{t}+1\right) \\
\frac{\partial \Pi}{\partial p_{2}}=\frac{1-a}{\alpha}\left(c_{e}-2 p_{2}+\alpha-\rho c_{e}+\rho c_{t}\right)
\end{gathered}
$$

Let $\frac{\partial \Pi}{\partial p_{1}}=0, \frac{\partial \Pi}{\partial p_{2}}=0$, get the best price:

$$
\begin{aligned}
& p_{1}^{*}=\frac{1+c_{e}+\rho c_{t}-\rho c_{e}}{2} \\
& p_{2}^{*}=\frac{\alpha+c_{e}+\rho c_{t}-\rho c_{e}}{2}
\end{aligned}
$$

\section{Appendix 2}

Proof 2: Find the Hesse matrix for $p_{1}^{b}, p_{2}^{b}$ and $p_{12}$.

$$
\begin{aligned}
H & =\left[\begin{array}{ccc}
\frac{\partial^{2} \Pi}{\partial p_{1}^{b 2}} & \frac{\partial^{2} \Pi}{\partial p_{1}^{b} \partial p_{2}^{b}} & \frac{\partial^{2} \Pi}{\partial p_{1}^{b} \partial p_{12}} \\
\frac{\partial^{2} \Pi}{\partial p_{2}^{b} \partial p_{1}^{b}} & \frac{\partial^{2} \Pi}{\partial p_{2}^{b 2}} & \frac{\partial^{2} \Pi}{\partial p_{2}^{b} \partial p_{12}} \\
\frac{\partial^{2} \Pi}{\partial p_{12} \partial p_{1}^{b}} & \frac{\partial^{2} \Pi}{\partial p_{12} \partial p_{2}^{b}} & \frac{\partial^{2} \Pi}{\partial p_{12}^{2}}
\end{array}\right] \\
& =\left[\begin{array}{ccc}
-\frac{2 a}{1-\beta} & 0 & \frac{2 a}{1-\beta} \\
0 & -2(1-a)\left(\frac{1}{\alpha}+\frac{1}{\beta-\alpha}\right) & \frac{2(1-a)}{\beta-\alpha} \\
\frac{2 a}{1-\beta} & \frac{2(1-a)}{\beta-\alpha} & -\left(\frac{2(1-a)}{\beta-\alpha}+\frac{2 a}{\beta(1-\beta)}\right)
\end{array}\right]
\end{aligned}
$$


First order determinant is $\left|H_{1}\right|=-\frac{2 a}{1-\beta}<0$. The second order determinant is $\left|H_{2}\right|=\frac{4 a(1-a)}{1-\beta} \cdot\left(\frac{1}{\alpha}+\frac{1}{\beta-\alpha}\right)$, The third order determinant is $\left|H_{3}\right|=-\frac{8 a(1-a)}{\alpha(\beta-\alpha)(1-\beta)}$, because of $0<a<1$ and $\alpha<\beta<1$. So $\left|H_{2}\right|>0$ and $\left|H_{3}\right|<0$. Therefore, the Hesse matrices is a negative fixed matrix, and the profit function is a concave function.

\section{Appendix 3}

Proof 3: Since the profit function is established under the condition of $p_{1}^{b} \geq \frac{p_{12}-\omega \theta}{\beta}, \quad p_{2}^{b} \leq \frac{\alpha\left(p_{12}-\omega \theta\right)}{\beta}$, the Kuhn-Tucker theorem is used to find the optimal price $p_{1}^{b}, p_{2}^{b}$ and $p_{12}$.

Using the Kuhn-Tucker theorem to get:

$$
\begin{gathered}
a\left(1-\frac{p_{1}^{b}-p_{12}+\omega \theta}{1-\beta}\right)-a \frac{p_{1}^{b}-c_{t}}{1-\beta}+a \frac{p_{12}-c_{e}}{1-\beta}+\lambda_{1}=0 \\
(1-a)\left(\frac{p_{12}-p_{2}^{b}-\omega \theta}{\beta-\alpha}-\frac{p_{2}^{b}}{\alpha}\right)-(1-a) \frac{p_{2}^{b}-c_{t}}{\beta-\alpha}+(1-a) \frac{p_{12}-c_{e}}{\beta-\alpha}-\lambda_{2}=0 \\
a \frac{p_{1}^{b}-c_{t}}{1-\beta}+(1-a) \frac{p_{2}^{b}-c_{t}}{\beta-\alpha}+a\left(\frac{p_{1}^{b}-p_{12}+\omega \theta}{1-\beta}-\frac{p_{12}-\omega \theta}{\beta}\right) \\
+(1-a)\left(1-\frac{p_{12}-p_{2}^{b}-\omega \theta}{\beta-\alpha}\right)-\left[a \frac{1}{\beta(1-\beta)}+(1-a) \frac{1}{\beta-\alpha}\right]-\frac{\lambda_{1}}{\beta}+\frac{\alpha \lambda_{2}}{\beta}=0 \\
\lambda_{1}\left(\frac{p_{12}-\omega \theta}{\beta}-p_{1}^{b}\right)=0 \\
\lambda_{2}\left(p_{2}^{b}-\frac{\alpha\left(p_{12}-\omega \theta\right)}{\beta}\right)=0 \\
\lambda_{1}, \lambda_{2} \geq 0
\end{gathered}
$$

According to the Kuhn-Tucker condition, when $\lambda_{1} \neq 0, \frac{p_{12}-\omega \theta}{\beta}-p_{1}^{b}=0$ and the consumer who prefers product 1 will not purchase the bundled product. Similarly, when $\lambda_{2} \neq 0, p_{2}^{b}=\frac{\alpha\left(p_{12}-\omega \theta\right)}{\beta}$ and the consumer who prefers product 2 will not purchase product 2 , but will purchase the bundled product (12). In order to make all three products have sales, you need $\lambda_{1}=\lambda_{2}=0$. Then the best price is:

$$
\begin{aligned}
& p_{1}^{b *}=\frac{1}{2}\left(1+c_{t}\right) \\
& p_{2}^{b *}=\frac{1}{2}\left(\alpha+c_{t}\right)
\end{aligned}
$$




$$
p_{12}^{*}=\frac{1}{2}\left(\beta+c_{e}+\omega \theta\right)
$$

\section{Appendix 4}

Proof 4: Find the first derivative of $\theta$ for Equation (20):

$$
\frac{\partial \Delta D_{1}}{\partial \theta}=\frac{a \omega}{2 \beta}+\frac{(1-a) \omega}{2(\beta-\alpha)}+\frac{a \omega}{2 \beta(1-\beta)}>0
$$

The inequality indicating the difference between the demand for the bundled strategy and the demand for separate sales when the degree of substitution between the bundled product and the product increases will increase.

At the same time, let $\Delta D_{1}=0$, get:

$$
\begin{aligned}
\theta^{*}= & \frac{\left[(1-a)\left(\alpha^{2} \rho-\alpha-\alpha^{2}-\beta\right)+a \beta(2-2 \beta-\beta \rho)\right] c_{e}}{\omega \beta^{2} a-\omega(1-a)(\beta-\alpha)} \\
& +\frac{\left[(1-a)\left(2 \alpha-\alpha^{2} \rho+\beta\right)-a \beta \rho\right] c_{t}-(\alpha+\beta)^{2}}{\omega \beta^{2} a-\omega(1-a)(\beta-\alpha)}
\end{aligned}
$$

At $\theta \in\left(0, \theta^{*}\right)$, when sold separately, the sales of the product are greater than the sales of the product at the time of bundled sales. At $\theta \in\left(\theta^{*}, 1\right)$, when sold separately, the sales of the product are less than the sales of the product at the time of the bundle. 